\title{
Resource Footprints are Good Proxies of Environmental Damage
}

\author{
Zoran J. N. Steinmann, ${ }^{* \dagger}{ }^{\dagger}$ Aafke M. Schipper, ${ }^{\dagger, \|}$ Mara Hauck, ${ }^{\dagger, \perp}$ Stefan Giljum, ${ }^{\ddagger}$ Gregor Wernet, ${ }^{\S}$ \\ and Mark A. J. Huijbregts ${ }^{\dagger}$
}

${ }^{\dagger}$ Department of Environmental Science, Institute for Water and Wetland Research, Radboud University, Heyendaalseweg 135,6525 AJ Nijmegen, The Netherlands

${ }^{\ddagger}$ Institute for Ecological Economics, Vienna University of Economics and Business (WU), Welthandelsplatz 1, 1020 Vienna, Austria

${ }^{\S}$ Ecoinvent, Technoparkstrasse 1, 8057 Zurich, Switzerland

\section{Supporting Information}

ABSTRACT: Environmental footprints are increasingly used to quantify and compare environmental impacts of for example products, technologies, households, or nations. This has resulted in a multitude of footprint indicators, ranging from relatively simple measures of resource use (water, energy, materials) to integrated measures of eventual damage (for example, extinction of species). Yet, the possible redundancies among these different footprints have not yet been quantified. This paper analyzes the relationships between two comprehensive damage footprints and four resource footprints associated with 976 products. The resource footprints accounted for $>90 \%$ of the variation in the damage footprints. Human health damage was primarily associated with the energy footprint, via emissions resulting from fossil fuel combustion. Biodiversity damage was mainly related to the energy and land footprints, the latter being mainly determined by agriculture and forestry. Our results indicate that relatively simple resource footprints are highly representative of damage to human health and biodiversity.

\section{INTRODUCTION}

Apart from welfare and increased longevity, our modern industrialized society has brought unintended environmental and social impacts, for example on biodiversity and human health. As illustrated by the so-called DPSIR framework (Driver, Pressure, State, Impact, and Response), ${ }^{1}$ human needs (e.g., need for food) result in environmental pressures (e.g., use of fertilizer) which change the state of the environment (e.g., polluted surface water). This in turn results in impacts (e.g., biodiversity decline) and eventually a societal response to these impacts (e.g., reduced fertilizer use) (Figure 1 ). In line with this framework, biodiversity impacts are assessed by integrated assessment studies, such as the Millennium Ecosystem Assessment ${ }^{2}$ and the Global Biodiversity Outlooks, ${ }^{3}$ which quantify the influence of human drivers on species decline. Similarly, in the Global Burden of Disease studies the damage to human health of a number of (environmental) factors, such as fine particulate dust concentrations, is assessed in terms of Disability Adjusted Life Years. $^{4}$

For purposes of environmental accountability and efficient damage remediation, impacts on biodiversity or human health can be allocated to specific products, technologies, cities, or nations, resulting in so-called footprints. Different types of footprints have been developed. Damage footprints approximate the anthropogenic impact on human health and ecosystems by encompassing as many relevant resource extractions, substance emissions, and cause-effect pathways as possible. $^{5-8}$ The comprehensiveness of the damage footprints comes, however, at a cost. Not only do damage footprint calculations require large amounts of input data but also their outcomes are associated with large uncertainties because of the assumptions and simplifications made when quantifying intricate environmental cause-effect chains. ${ }^{5}$ As an alternative approach, the pressure part of the DPSIR chain can be used to quantify so-called resource footprints. ${ }^{9,10}$ Examples of resource footprint indicators include land use, water consumption, raw material extraction, and life cycle energy use. ${ }^{11-19}$ Because they are situated early on in the DPSIR chain, such resource footprint indicators are relatively straightforward to calculate and communicate, yet they are unlikely to represent the total environmental impact of a particular anthropogenic entity. ${ }^{20,21}$ For example, environmental impacts primarily due to emissions of toxic substances are poorly represented by resource footprints. $^{22,23}$ Moreover, certain footprints are considered overly simplistic for use in environmental assessments. For example, material footprints that merely sum the amounts of all raw materials needed fail to consider that the environmental impacts associated with their extraction and processing can be highly material-specific. ${ }^{24}$

In short, the different footprint approaches involve clear trade-offs between comprehensiveness and representativeness, on the one hand, and data requirements, computational efforts,

Received: February 7, 2017

Revised: $\quad$ May 8, 2017

Accepted: May 16, 2017

Published: May 26, 2017 


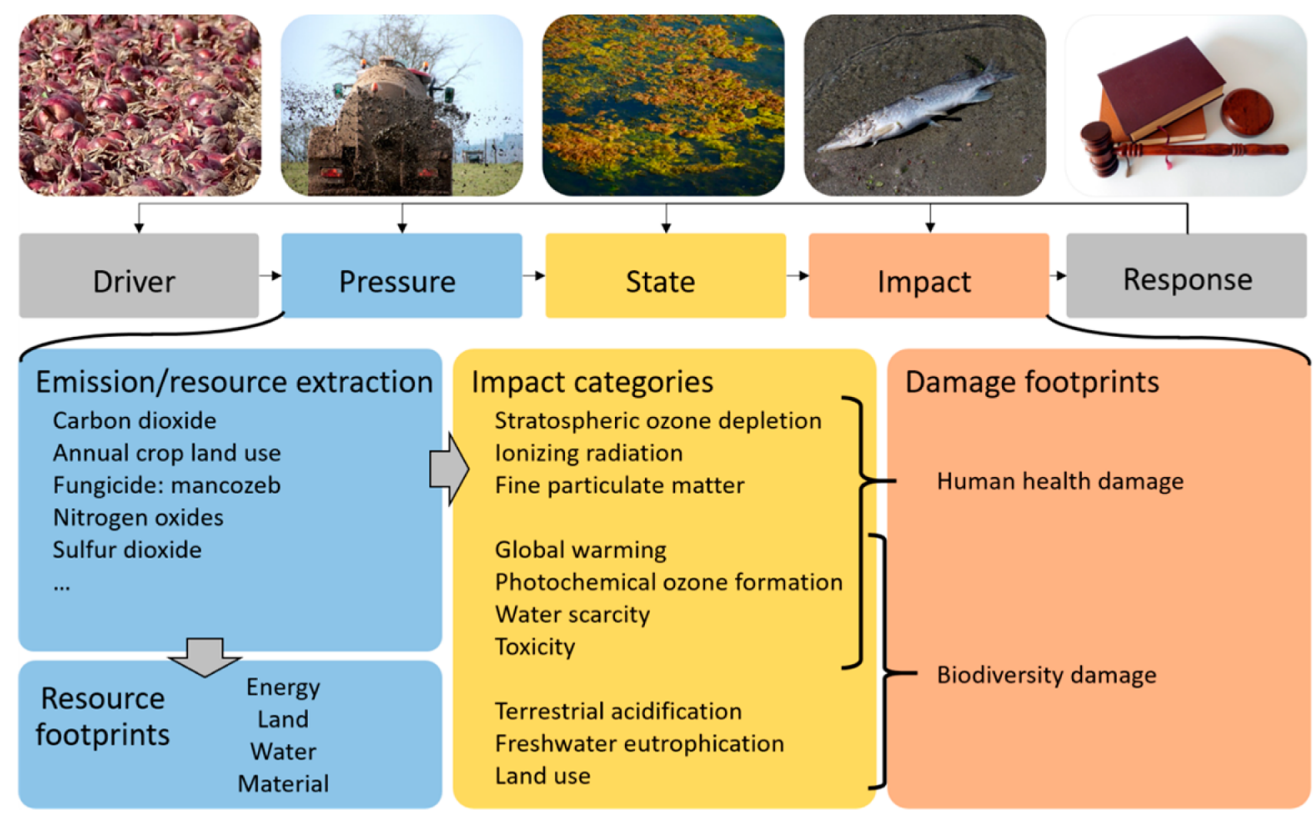

Figure 1. Schematic overview of the DPSIR chain and calculation of resource and damage footprints. The DPSIR chain shows how a primary human need (Driver), such as the need for food (onions), may lead to a resource extraction or substance emission, in this case fertilizer application (Pressure), resulting in a change in the abiotic environment, like eutrophication (State), a corresponding ecological response, like fish death (Impact), and eventually a societal reaction, such as environmental legislation on fertilizer application (Response). Resource and damage footprints are calculated based on all emission and resource extractions (located in the Pressure part of the DPSIR chain) that are associated with the production of, in this case, $1 \mathrm{~kg}$ of onions. Emissions, extractions, and resource footprints are retrieved from the ecoinvent database. The five emissions/resource extractions that ultimately contribute most to biodiversity damage induced by onion production are displayed. The state of the environment is calculated via different routes in several impact categories, which can ultimately result in damage to human health, biodiversity damage, or both. The ReCiPe methodology provides the factors necessary to convert the amount of emissions/resource extractions into environmental damage.

and reliability, on the other. A vital question in this context, therefore, is how damage footprints are connected to the more straightforward resource footprints. ${ }^{11,22,25}$ Various studies investigated mutual correlations among footprint indicators. $^{26-29}$ These studies focused on quantifying redundancies among different types of indicators and generally found that 4 to 6 indicators are enough to cover virtually all variance among different footprint indicators. Other studies looked specifically at resource-damage relationships ${ }^{22,30}$ but considered bivariate relationships only, demonstrating that the cumulative energy demand was a useful proxy for environmental damage for most product categories, except for biobased products. Up to now, the relationship between multiple resource and damage footprints has never been systematically quantified. Knowledge of the relationships between both sets of indicators will clarify the extent to which resource footprints may serve as proxies for damage to humans and biodiversity.

In this study, we analyzed the relationships between two state-of-the-art damage footprints and four resource footprints associated with the manufacturing of 976 products (Supporting Information data file S1). Damage footprints pertain to human health and biodiversity, which are expressed in years of disabled life or shortened lifespans and in local species losses, respectively. Resource footprints reflect the use of fossil energy, raw materials, land, and water. To quantify the damage and resource footprints associated with each product, we used resource use and emission data from the ecoinvent database (v3.1). ${ }^{31}$ To quantify damage to human health and biodiversity, we multiplied the products' resource uses and emissions with so-called characterization factors that aggregate relevant environmental cause-effect pathways (Figure 1), thus yielding an estimate of the total amount of damage per unit of resource use or emission for each product. ${ }^{32,33}$ We then applied multiple log-linear regression to link each of the two damage footprints to the four resource footprints. To elucidate the primary causeeffect pathways underlying the relationships between the damage and resource footprints, we calculated the contribution of each emission and resource use to the two damage footprints of each of the 976 products.

\section{METHODS}

Product Selection and Life Cycle Scope. We based our analysis on the ecoinvent database (version 3.1). This database contains "cradle-to-gate" life-cycle data on 1,597 types of emissions representing numerous substances emitted to various environmental compartments (air, water, and soil) and 272 entries regarding the use of resources, including groundwater and surface water, fossil fuels, minerals, and various types of land cover. For our analysis we selected all products with emissions and resource extractions expressed per kg of product. The "cradle-to-gate" life cycle perspective of the database implies that we covered the production part of the products' life cycles, thus including resource use and damage from extraction of the raw materials up to the delivery to the market. Following the product selection procedure by Steinmann and coworkers, ${ }^{29}$ we applied the following selection criteria to minimize overlap between products:

- Individual products (e.g., concrete block) were preferred over aggregated categories (e.g., "construction materials").

- For identical products, for which different production regions or production methods were available, we selected the 
global or "rest-of-the-world" market mix instead of specific subtypes based on particular production methods or regions.

- Some products share (almost) identical production chains (such as isobutanol and butanol). In these cases we selected the products with the largest overall amount of interventions.

Similarity among the product chains was checked by dividing all interventions related to the production of $1 \mathrm{~kg}$ of a product by all the interventions of all other products. In case of an identical production chain, the ratios for all interventions are the same. Two products were considered to come from the same production chain if the coefficient of variation of these ratios was $<0.01$. Like in the paper by Steinmann and coworkers $^{29}$ the final set contained 976 products, from seven categories: Agricultural \& forestry products (106), Building materials (72), Chemicals (435), Metal products \& electronics (128), Ores, minerals \& fuels (91), Plastics (64), and Processed biobased products (80) (see data file S1 for the names of all products).

Resource Footprints. We quantified four resource footprints for each product: nonrenewable energy demand, raw material use, land use, and freshwater consumption. Energy demand (MJ) was quantified as the total amount of fossil energy required, including energy from oil, coal, gas, and peat. Raw material use $(\mathrm{kg})$ was calculated as the total amount of all raw materials extracted from the earth, excluding fossil fuels because these were already covered by the energy demand calculations. Biotic resources were not included in the material footprint. Metal extractions as reported in ecoinvent were converted to ore extractions by dividing by the metal-specific ore grades, as reported in ecoinvent. ${ }^{31}$ In case of multiple metals derived from the same ore (e.g., silver and gold), we used the maximum ore extraction needed to obtain the required amount of any of the metals, in order to avoid double counting of ore produced. The land footprint $\left(\mathrm{m}^{2} \cdot \mathrm{yr}\right)$ was quantified as the total area of land used over time, irrespective of the type of land use, and not including land transformation. The employed blue water footprint covers the life cycle consumptive use of water. Freshwater consumption $\left(\mathrm{m}^{3}\right)$ was defined as the amount of evaporated water plus the amount of water that is incorporated in the products. This consumption was calculated as the difference between freshwater extracted from nature and the amount of water returned. In 245 out 976 cases the water evaporation (calculated by summing all emissions of water to the air) exceeded the amount of extracted water minus the amount of returned water. In these cases the evaporation was used as approximation of the total water consumption.

Damage Footprints. We calculated the human health and biodiversity damage footprints of each product by summing the resource uses and emissions multiplied with the corresponding characterization factors (CFs), i.e. factors representing the amount of damage per unit of resource use or emission, as

$$
\mathrm{DF}_{x, p}=\sum_{i} I_{i, p} \cdot \mathrm{CF}_{i, x}
$$

where $\mathrm{DF}_{x, p}$ is the damage footprint for category $x$ (human health or biodiversity) and product $p, I_{i, p}$ is the amount of resource use or emission $i$ associated with product $p$, and $\mathrm{CF}_{i x}$ is the characterization factor for resource use or emission $i$ and damage category $x$ (damage to human health or biodiversity). ${ }^{34}$ We calculated human health damage as disability-adjusted life years (DALYs; yr) induced by climate change, stratospheric ozone depletion, toxicant exposure, photochemical ozone formation, particulate matter formation, water stress, and ionizing radiation. ${ }^{32}$ Biodiversity loss was calculated as the time-integrated local species loss (species - yr) due to climate change, terrestrial acidification, photochemical ozone formation, freshwater eutrophication, terrestrial ecotoxicity, freshwater ecotoxicity, marine ecotoxicity, water stress, agricultural land occupation, and urban land occupation. ${ }^{32}$ See Supporting Information Table S1 for a more detailed description of the impact pathways considered in these impact categories and the sources of the underlying data.

To account for spatial variability in damage we used countryspecific CFs for acidification, freshwater eutrophication, and water consumption and region-specific CFs for fine particulate matter formation and photochemical ozone formation. There were 156 countries for which acidification, freshwater eutrophication, and water consumption CFs were provided by the ReCiPe methodology. ${ }^{32}$ Each of these countries was assigned to one of the 58 regions for fine particulate matter formation and photochemical ozone formation (Supporting Information data file S2).

To avoid artificial environmental benefits for human health and biodiversity, net negative emissions of metals to agricultural soils due to metal uptake in crops, as reported in ecoinvent v3.1, were not considered in our cradle-to-gate analysis. Furthermore, we neglected potential human health impacts of pesticide uptake by crops, as we did not have information whether the crops were used for food, feed, or biofuels. Finally, only the off-target biodiversity impacts of chemical emissions to agricultural soil were considered. This was done to avoid double counting with the biodiversity impact caused by agricultural land occupation.

Regression Modeling. We used multiple linear regression (least-squares fitting) to relate the damage footprints to the resource footprints. To account for spatial variability in impacts, we performed the regression analysis for each of the 156 countries separately, thereby implicitly assuming that all emissions and resource extractions required for each of the 976 products occur in that specific country. Because the footprints varied up to 10 orders of magnitude (based on all products), all footprints were log-transformed prior to model fitting. In regression models, high correlations among explanatory variables (in our case, the resource footprints) lead to unstable regression coefficients. If this is the case, it becomes impossible to determine which of the predictors is responsible for which share of the variance. ${ }^{35,36}$ Therefore, we fitted all possible combinations of predictors and removed the regression models for which any of the predictors had a Variance Inflation Factor (VIF) larger than $5 .{ }^{35}$ We then ranked the remaining models according to Akaike's Information Criterion (AIC) ${ }^{37}$ which enabled us to select the most parsimonious model per country, damage footprint, and product group (Supporting Information Table S2). We calculated Cook's distances for the full model set to assess the influence of individual products on the regression coefficients. ${ }^{38}$ Cook's distances were below the threshold of 1 in all cases; therefore, all individual products were retained in the analysis. All analyses were performed in the statistical program $\mathrm{R}^{39}$ Plotting of all figures except Figure 1 was performed with the package "Cairo", ${ }^{40}$ and VIFs were calculated with the package "HH". ${ }^{41}$ Plots of the model residuals were created to analyze the accuracy of the predictions as well as check for potential violations of regression assumptions (Supporting Information Figures S7 and S8). 

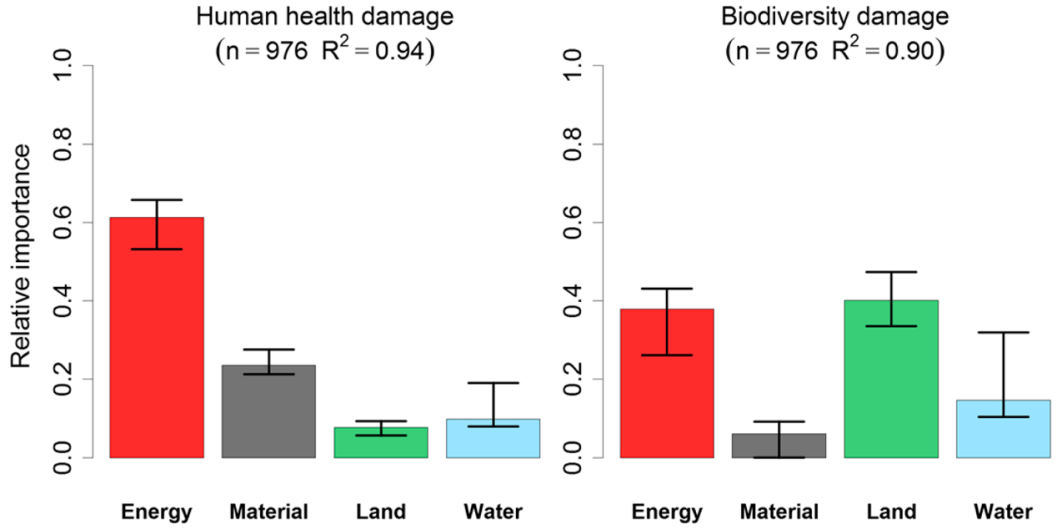

Figure 2. Associations between human health damage (left) and biodiversity damage (right) and four resource footprints (Energy, Material, Land, Water). The relative importance is expressed as standardized coefficients of log-linear regression models based on 976 products. Error bars display the $90 \%$ confidence interval in predictor importance, resulting from spatial variability in damage. $R^{2}$ was calculated as the mean value obtained from the 156 country-specific regression models.

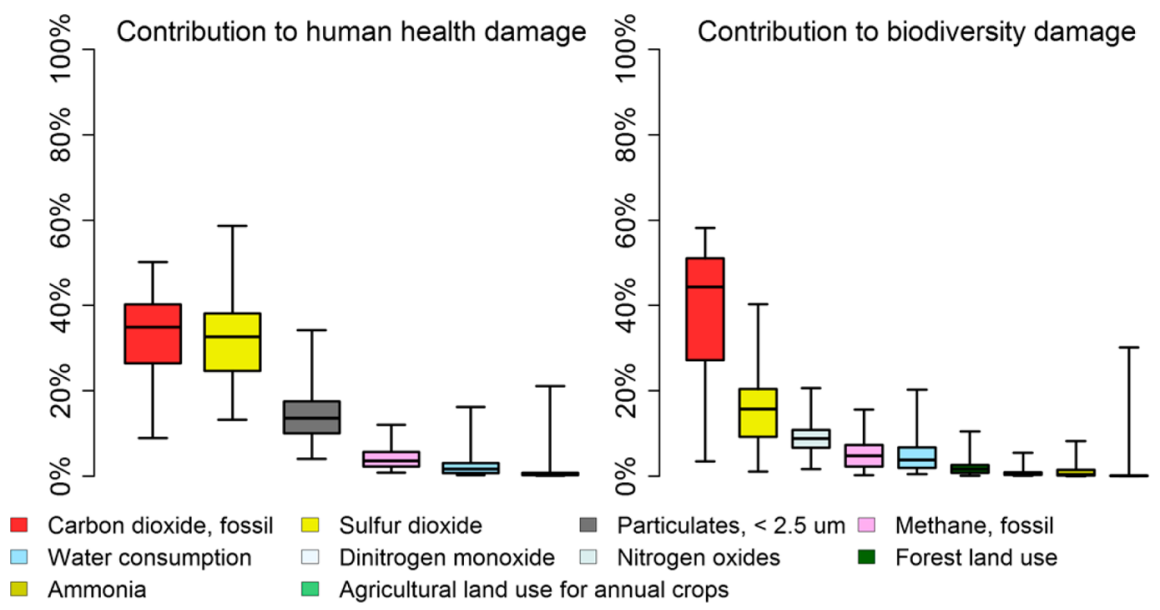

Figure 3. Contributions of major resource extractions or substance emissions to human health damage (left) and biodiversity damage (right). Boxplots represent quartiles and $90 \%$ intervals encompassing the 976 products.

The plots revealed that the errors in the prediction did not systematically deviate from the expected normal distribution.

Cause-Effect Pathways. To elucidate the relationships between the damage and resource footprints, we first calculated the contribution of each individual resource extraction or emission to the damage to human health or biodiversity of each product, as

$$
\mathrm{FF}_{x, i, p}=\frac{I_{i, p} \cdot \mathrm{CF}_{i, x}}{\sum_{i} I_{i, p} \cdot \mathrm{CF}_{i, x}}
$$

where $\mathrm{FF}_{x, i, p}$ is the fraction of the damage footprint of product $p$ for category $x$ (human health or biodiversity) caused by resource extraction or emission $i, I_{i, p}$ is the amount of resource extraction or emission $i$ associated with product $p$, and $\mathrm{CF}_{i x}$ is the characterization factor for resource extraction or emission $i$ and damage category $x$. Per damage footprint, we ranked the median contributions $\mathrm{FF}_{x, i p p}$ over all products and per product group. This analysis was performed only for the default ReCiPe characterization factors, i.e. country-specific differences due to spatial variability were not included.

Damage Scenarios. Damage footprint calculations require particular assumptions and choices, for example with respect to the time horizon considered, the cause-effect pathways to be included, and the expected ability of humans and ecosystems to mitigate or adjust to future damage. In the ReCiPe methodology, these assumptions and choices are aggregated in three scenarios that reflect differences in value choices based on Cultural theory considerations. ${ }^{42-44}$ Each of these scenarios is represented by a coherent set of characterization factors. To assess the influence of these different scenarios on our results, we performed the damage footprint calculations and subsequent regression analyses based not only on the characterizations of the default scenario but also according to the two other scenarios. The "high resilience" scenario assumes that ongoing technological and economic developments enable mankind to mitigate future damage, therefore giving more weight to present-day effects than future damage and accounting only for well-established cause-effect relationships. The "low resilience" scenario reflects the view that nature is fragile, that all possible cause-effect paths need to be accounted for (precautionary principle), and that a long time horizon is most adequate.

\section{RESULTS}

Human Health Damage. Overall, the four resource footprints accounted for more than $90 \%$ of the variation in human health damage. Human health damage was primarily associated with fossil energy use, followed by the use of raw 
materials, water, and land (Figure 2, Supporting Information Figures S1 and S2). The strong association between human health damage and fossil energy use reflects adverse health effects due to the emissions of carbon dioxide $\left(\mathrm{CO}_{2}\right)$, fine particulate matter, and sulfur dioxide $\left(\mathrm{SO}_{2}\right)$ associated with the combustion of fossil fuels (Figure 2 and Supporting Information Figure S3). Emissions of $\mathrm{CO}_{2}$ and other greenhouse gases lead to climate change, which in turn lead to increased malnutrition due to crop failures and increased transmission of infectious diseases. ${ }^{45}$ Fine particulate matter, including sulfur aerosols produced by $\mathrm{SO}_{2}$ emissions, has adverse effects particularly on people suffering from lung or heart diseases. ${ }^{46,47}$ As the small error bars indicate (Figure 2), the associations between damage and resource footprints were not sensitive to spatial variation in impacts between the 156 countries included in our analysis.

Biodiversity Damage. The four resource footprints also accounted for at least $90 \%$ of the damage to biodiversity (Figure 2, Supporting Information Figures S4 and S5). Overall, damage to biodiversity could be approximated in particular by the combination of the land and energy footprints. Land use is generally acknowledged as an important driver of biodiversity loss because it leads to the destruction or modification of natural habitats. ${ }^{48,49}$ The importance of fossil energy demand is primarily attributed to $\mathrm{CO}_{2}$ emissions associated with fossil-fuel combustion (Figure 3 and Supporting Information Figure S6). Climate change induced by these emissions may result in biodiversity loss through shifts or reductions in the ranges of species. ${ }^{48,50}$ Acidification as a result of $\mathrm{SO}_{2}$ emissions also had a relatively large contribution to the overall biodiversity damage (Figure 3). The relative impacts of the resource footprints showed more variation among the 156 countries than for human health impacts (Figure 2). This is due to biodiversity damage by water stress being highly location-specific, with higher impacts in countries with greater water scarcity.

\section{DISCUSSION}

Over the past 20 years, a variety of footprint assessment methods have been developed, ranging from relatively simple resource- or emission-based indicators to more comprehensive damage-based indicators. Recently, an explicit call has been made for the various methods to be harmonized and for the representativeness of the resource-based footprints to be evaluated. ${ }^{11}$ Using a comprehensive damage assessment methodology and state-of-the-art life-cycle data associated with a large number of products, we found that four relatively straightforward resource footprints accounted for the majority of the variation in damage to human health and biodiversity.

The ecoinvent 3 database, as used in our study, is comprehensive in terms of included environmental flows and also has a clear set of data quality guidelines. Similarly, the ReCiPe 2016 method is a state-of-the-art method to quantify damage on an end point level. Other impact assessment methods might use different characterization factors and therefore come to different estimations of the environmental damage. However, studies aimed at comparing different impact assessment methods generally find very strong correlations between impact categories from different methods. ${ }^{26-29}$ These findings make it likely that the choice of impact assessment method is not very influential. Our findings are also consistent with independent studies that acknowledge the importance of energy and land use as primary drivers of human health and biodiversity impacts. ${ }^{2-4}$ Our study is, however, not without limitations. One limitation is that not all emissions related to the products' life cycles are reported in the ecoinvent database. For example, emissions of nanoparticles are not included, and therefore any potential damage that these may cause to biodiversity or human health cannot be included either. A second limitation is that in the ReCiPe method not all impacts are included, such as ocean acidification, which would also lead to an underestimation of the biodiversity damage footprint. Both of these limitations may result in weaker correlations between resource and damage footprints, if the missing emissions or damage pathways are unrelated to overall resource use. A third limitation is that we focused on the "cradle-to-gate" phase of the products' life cycles. We do expect, however, that the resource footprints are also representative of the environmental damage caused during the use and waste phases ("gateto-grave"). For example, for buildings and household appliances, damages from the use and waste phases are dominated by energy and/or water use. ${ }^{51,52}$

The relationships observed between resource and most of the analyzed damage footprints were consistent across product groups (Supporting Information Figures S1 and S4), countries, and assumptions used in the damage calculations. The latter can be observed from the similarity among the results of the default damage, high-resilience, and low resilience scenarios, which represent three coherent sets of assumptions commonly used in environmental impact assessments (Supporting Information Figures S2 and S5). There were only three main exceptions to these general findings, resulting in lower explanatory power of the resource footprints or shifts in their relative importance. First, particularly if the damage of a particular entity is primarily caused by process-specific emissions of toxic substances, the resource footprints are less representative of the damage. For human health damage, this was the case for plastics and building materials $\left(R^{2} \approx 70-80 \%\right.$, Supporting Information Figure S1). The manufacturing of some of these products is associated with substantial processspecific emissions of certain substances. During the manufacture of some plastics for example, long-lived hydrochlorofluorocarbons are emitted which lead to ozone depletion and global warming, resulting in human health damage not closely related to overall amounts of resource use. For biodiversity damage, the explanatory power of the four resource footprints was slightly lower for plastics $\left(R^{2}=71 \%\right)$ and processed biobased products $\left(R^{2}=84 \%\right)$ (Supporting Information Figure S4), because the global warming effect of certain processspecific emissions is not well-captured by the resource footprints. Second, the associations between biodiversity damage and resource footprints tended to vary across products. For example, the damage from agricultural, forestry, and biobased products was primarily due to land use, whereas the impacts of the other product groups were primarily related to fossil energy use (Supporting Information Figures S4 and S6). Third, the relative contributions of land and energy use also varied depending on whether the damage calculations followed a default or high-resilience as opposed to a low-resilience scenario (Supporting Information Figure S5). In the lowresilience scenario, which assumes a limited capability of humans and ecosystems to adjust to change, the damage is calculated over a time horizon longer than the default of 100 years. This results in a substantial increase in the contribution of the energy footprint at the expense of the contribution of the land footprint. 
Critics of resource footprints argue that environmental impacts cannot be adequately captured by simple, onedimensional indicators, whereas their advocates stress that the simplifications involved are necessary to ensure that the indicators speak to policy makers and the general public. ${ }^{10,11,53}$ By relating two comprehensive damage indicators to four straightforward resource footprints, we have demonstrated that resource footprints are representative screening indicators of damage to human health and biodiversity. Our analysis further revealed that human health damage is primarily induced by fossil energy use, whereas biodiversity damage is primarily related to both land and fossil energy use. Thus, we conclude that energy and land footprints provide valuable proxies for the overall environmental damage produced by a particular entity.

\section{ASSOCIATED CONTENT}

\section{S Supporting Information}

The Supporting Information is available free of charge on the ACS Publications website at DOI: 10.1021/acs.est.7b00698.

Figure S1, associations between human health damage and four resource footprints per product group; Figure S2, associations between human health damage and four resource footprints for two alternative sets of characterization factors, based on high resilience and low resilience; Figure S3, contributions to human health damage (per product group) of most important contributors; Figure S4, associations between biodiversity damage and four resource footprints per product group; Figure S5, associations between biodiversity damage and four resource footprints for two alternative sets of characterization factors, based on high resilience and low resilience; Figure S6, contributions biodiversity damage (per product group) of most important contributors; Figure S7, residuals of the regression models for human health damage for all the products and per product category; Figure S8, residuals of the regression models for biodiversity damage for all the products and per product category; Table S1, included impact categories in $\mathrm{ReCiPe}$, covered areas of protection, and damage pathways; Table S2, goodness of fit and coefficients of log-linear regression models (PDF)

Data file S1, list of included products; data file S2, list of included countries and regions (XLSX)

\section{AUTHOR INFORMATION}

\section{Corresponding Author}

*Phone: +31 24365 2393. E-mail: z.steinmann@science.ru.nl. ORCID

Zoran J. N. Steinmann: 0000-0001-8606-917X

\section{Present Addresses}

"PBL Netherlands Environmental Assessment Agency, Bezuidenhoutseweg 30, 2594 AC, The Hague.

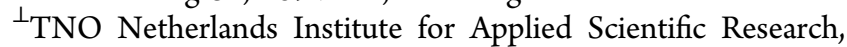
Princetonlaan 6, 3584 CB Utrecht, The Netherlands.

\section{Notes}

The authors declare no competing financial interest.

\section{ACKNOWLEDGMENTS}

We thank the European Commission for supporting this research project (Desire project, number 308552).

\section{REFERENCES}

(1) Smeets, E.; Wetering, R. Environmental Indicators:Typology and Overview; Technical report No 25/1999; European Environmental Agency, 1999; https://www.eea.europa.eu/ds_resolveuid/ ZATOEJRPDX (accessed May 23, 2017).

(2) Ecosystems and Human Well-being: Synthesis; Millennium Ecosystem Assessment, Island Press: Washington, DC, 2005.

(3) Global Biodiversity Outlook 4; Secretariat of the Convention on Biological Diversity: Montréal, Canada, 2014.

(4) GBD 2013 Risk Factors Collaborators. GBD 2013 Risk Factors Collaborators Global, regional, and national comparative risk assessment of 79 behavioural, environmental and occupational, and metabolic risks or clusters of risks in 188 countries, 1990-2013: a systematic analysis for the Global Burden of Disease Study 2013. Lancet 2015, 386, 2287-2323.

(5) Hellweg, S.; Milà i Canals, L. Emerging approaches, challenges and opportunities in life cycle assessment. Science 2014, 344 (6188), $1109-1113$.

(6) Hauschild, M. Z. Assessing environmental impacts in a life-cycle perspective. Environ. Sci. Technol. 2005, 39 (4), 81A-88A.

(7) Bjørn, A.; Diamond, M.; Birkved, M.; Hauschild, M. Z. Chemical Footprint Method for Improved Communication of Freshwater Ecotoxicity Impacts in the Context of Ecological Limits. Environ. Sci. Technol. 2014, 48, 13253-13262.

(8) Nordborg, M.; Arvidsson, R.; Finnveden, G.; Cederberg, C.; Sörme, L.; Palm, V.; Stamyr, K.; Molander, S. Updated indicators of Swedish national human toxicity and ecotoxicity footprints using USEtox 2.01. Environ. Impact Assess. Rev. 2017, 62, 110-114.

(9) Tukker, A.; Bulavskaya, T.; Giljum, S.; de Koning, A.; Lutter, S.; Simas, M.; Stadler, K.; Wood, R. Environmental and resource footprints in a global context: Europe's structural deficit in resource endowments. Glob Environ. Change 2016, 40, 171-181.

(10) Giljum, S.; Burger, E.; Hinterberger, F.; Lutter, S.; Bruckner, M. A comprehensive set of resource use indicators from the micro to the macro level. Resour Conserv Recycl 2011, 55 (3), 300-308.

(11) Hoekstra, A. Y.; Wiedmann, T. O. Humanity's unsustainable environmental footprint. Science 2014, 344 (6188), 1114-1117.

(12) Bruckner, M.; Giljum, S.; Lutz, C.; Wiebe, K. S. Materials embodied in international trade - global material extraction and consumption between 1995 and 2005. Glob Environ. Change 2012, 22 (3), 568-576.

(13) Feng, K.; Chapagain, A.; Suh, S.; Pfister, S.; Hubacek, K. Comparison of bottom-up and top-down approaches to calculating the water footprints of nations. Econ Syst. Res. 2011, 23 (4), 371-385.

(14) Giljum, S.; Bruckner, M.; Martinez, A. Material footprint assessment in a global input-output framework. J. Ind. Ecol. 2015, 19 (5), 792-804.

(15) Hoekstra, A. Y.; Mekonnen, M. M. The water footprint of humanity. Proc. Natl. Acad. Sci. U. S. A. 2012, 109 (9), 3232-3237.

(16) Wiedmann, T. O.; Schandl, H.; Lenzen, M.; Moran, D.; Suh, S.; West, J.; Kanemoto, K. The material footprint of nations. Proc. Natl. Acad. Sci. U. S. A. 2015, 112 (20), 6271-6276.

(17) Weinzettel, J.; Hertwich, E. G.; Peters, G. P.; Steen-Olsen, K.; Galli, A. Affluence drives the global displacement of land use. Glob Environ. Change 2013, 23 (2), 433-438.

(18) Yu, Y.; Feng, K.; Hubacek, K. Tele-connecting local consumption to global land use. Glob Environ. Change 2013, 23 (5), $1178-1186$

(19) Arvidsson, R.; Svanström, M. A framework for energy use indicators and their reporting in life cycle assessment. Integr. Environ. Assess. Manage. 2016, 12, 429-436.

(20) Galli, A.; Wiedmann, T.; Ercin, E.; Knoblauch, D.; Ewing, B.; Giljum, S. Integrating ecological; carbon and water footprint into a "footprint family" of indicators: definition and role in tracking human pressure on the planet. Ecol. Indic. 2012, 16, 100-112.

(21) Fiala, N. Measuring sustainability: why the ecological footprint is bad economics and bad environmental science. Ecol Econ 2008, 67 (4), 519-525. 
(22) Huijbregts, M. A. J.; Hellweg, S.; Frischknecht, R.; Hendriks, H. W.; Hungerbühler, K.; Hendriks, A. J. Cumulative energy demand as predictor for the environmental burden of commodity production. Environ. Sci. Technol. 2010, 44 (6), 2189-2196.

(23) Laurent, A.; Olsen, S. I.; Hauschild, M. Z. Limitations of carbon footprint as indicator of environmental sustainability. Environ. Sci. Technol. 2012, 46 (7), 4100-4108.

(24) van der Voet, E.; van Oers, L.; Nikolic, I. Dematerialisation: not just a matter of weight. J. Ind. Ecol 2005, 8 (4), 121-137.

(25) Fang, K.; Heijungs, R.; de Snoo, G. R. Theoretical exploration for the combination of the ecological; energy; carbon; and water footprints: overview of a footprint family. Ecol. Indic. 2014, 36, 508518.

(26) Röös, E.; Sundberg, C.; Tidåker, P.; Strid, I.; Hansson, P. A. Can carbon footprint serve as an indicator of the environmental impact of meat production? Ecol. Indic. 2013, 24, 573-581.

(27) Berger, M.; Finkbeiner, M. Correlation analysis of life cycle impact assessment indicators measuring resource use. Int. J. Life Cycle Assess. 2011, 16 (1), 74-81.

(28) Lasvaux, S.; Achim, F.; Garat, P.; Peuportier, B.; Chevalier, J.; Habert, G. Correlations in Life Cycle Impact Assessment methods (LCIA) and indicators for construction materials: What matters? Ecol. Indic. 2016, 67, 174-182.

(29) Steinmann, Z. J. N.; Schipper, A. M.; Hauck, M.; Huijbregts, M. A. J. How many environmental impact indicators are needed in the evaluation of product life cycles? Environ. Sci. Technol. 2016, 50 (7), 3913-3919.

(30) Kalbar, P. P.; Birkved, M.; Karmakar, S.; Nygaard, S. E.; Hauschild, M. Can carbon footprint serve as proxy of the environmental burden from urban consumption patterns? Ecol. Indic. 2017, 74, 109-118.

(31) Moreno Ruiz, E.; Weidema, B. P.; Bauer, C.; Nemecek, T.; Vadenbo, C. O.; Treyer, K.; Wernet, G. Documentation of changes implemented in ecoinvent data 3.0; Ecoinvent Report 5; 2013; 3.

(32) Huijbregts, M. A. J.; Steinmann, Z. J. N.; Elshout, P. M. F.; Stam, G.; Verones, F.; Vieira, M. D. M.; Hollander, A.; Zijp, M.; van Zelm, R. ReCiPe 2016: A harmonized life cycle impact assessment method at midpoint and endpoint level. Report 1: Characterization; 2016. http://www.ru.nl/environmentalscience/research/themes-0/ life-cycle/projects/ (accessed September 27, 2016).

(33) Goedkoop, M. J.; Heijungs, R.; Huijbregts, M.; De Schryver, A.; Struijs, J.; Van Zelm, R. ReCIPe 2008: A Life Cycle Impact Assessment Method which Comprises Harmonised Category Indicators at the Midpoint and the Endpoint Level. Report 1: Characterisation; 2009. http://www.lcia-recipe.net (accessed September 27, 2016).

(34) Hauschild, M. Z.; Huijbregts, M. A. J. Life cycle impact assessment; Springer: Dordrecht, The Netherlands, 2015; DOI: 10.1007/978-94-017-9744-3.

(35) Field, A. Discovering Statistics Using SPSS, 3rd ed.; SAGE Publications Ltd.: London, 2009.

(36) Zuur, A. F.; Ieno, E. N.; Walker, N. J.; Saveliev, A. A.; Smith, G. M. Mixed Effect Models and Extensions in Ecology with R; Springer Verlag: New York, 2009; DOI: 10.1007/978-0-387-87458-6.

(37) Akaike, H. A new look at the statistical model identification.

IEEE Trans. Autom. Control 1974, 19 (6), 716-723.

(38) Cook, R. D.; Weisberg, S. Residuals and Influence in Regression; Chapman \& Hall: New York, 1982.

(39) R Core Team R: A Language and Environment for Statistical Computing; R Foundation for Statistical Computing: Vienna, Austria, 2012. http://www.R-project.org/ (accessed September 27, 2016).

(40) Urbanek, S.; Horner, J. Cairo: R Graphics Device Using Cairo Graphics Library For Creating High-Quality Bitmap (PNG; JPEG; TIFF); Vector (PDF; SVG; Postscript) and Display (X11 and Win32) Output; R package version 1.5-5; 2012. http://CRAN.R-project.org/ package=Cairo (accessed September 27, 2016).

(41) Heiberger, R. M. HH: Statistical Analysis and Data Display: Heiberger and Holland; R package version 2.3-42; 2013. http://CRAN. R-project.org/package $=\mathrm{HH}$ (accessed September 27, 2016).
(42) De Schryver, A. M.; van Zelm, R.; Humbert, S.; Pfister, S.; McKone, T. E.; Huijbregts, M. A. J. Value choices in life cycle impact assessment of stressors causing human health damage. J. Ind. Ecol. 2011, 15 (5), 796-815.

(43) Thompson, M.; Ellis, R.; Wildavsky, A. Cultural Theory; Westview Press: Boulder, CO, 1990.

(44) Hofstetter, P.; Baumgartner, T.; Scholz, R. W. Modelling the valuesphere and the ecosphere: integrating the decision makers' perspectives into LCA. Int. J. Life Cycle Assess. 2000, 5 (3), 161-175.

(45) Watts, N.; et al. Health and climate change: policy responses to protect human health. Lancet 2015, 386, 1861-1914.

(46) Lelieveld, J.; Evans, J. S.; Fnais, M.; Giannadaki, D.; Pozzer, A. The contribution of outdoor air pollution sources to premature mortality on a global scale. Nature 2015, 525, 367-371.

(47) Brauer, M.; et al. Ambient air pollution exposure estimation for the global burden of disease 2013. Environ. Sci. Technol. 2016, 50 (1), 79-88.

(48) Alkemade, R.; van Oorschot, M.; Miles, L.; Nellemann, C.; Bakkenes, M.; ten Brink, B. GLOBIO3: A framework to investigate options for reducing global terrestrial biodiversity loss. Ecosystems 2009, 12 (3), 374-390.

(49) Newbold, T.; et al. Global effects of land use on local terrestrial biodiversity. Nature 2015, 520, 45-50.

(50) Urban, M. C. Accelerating extinction risk from climate change. Science 2015, 348 (6234), 571-573.

(51) Blengini, G. A.; Di Carlo, T. The changing role of life cycle phases; subsystems and materials in the LCA of low energy buildings. Energy Build 2010, 42 (6), 869-880.

(52) Analysis of the Life Cycle Impacts and Potential for Avoided Impacts Associated with Single Family Homes; EPA Publication 530-R13-004; U.S. Environmental Protection Agency: 2013.

(53) Lifset, R. Frontiers in footprinting. J. Ind. Ecol. 2014, 18 (1), 13. 